\title{
Dynamic corner frequency in source spectral model for stochastic synthesis of ground motion*
}

\author{
Xiaodan Sun ${ }^{1, \uparrow}$ Xiaxin Tao ${ }^{1,2}{\text { Guoxin } \text { Wang }^{3}}^{3}$ and Taojun Liu ${ }^{1}$ \\ ${ }^{1}$ Department of Civil Engineering, Harbin Institute of Technology, Harbin 150090, China \\ 2 Institute of Engineering Mechanics, China Earthquake Administration, Harbin 150080, China \\ ${ }^{3}$ Department of Civil and Hydraulic Engineering, Dalian University of Technology, Dalian 116024, China
}

\begin{abstract}
The static corner frequency and dynamic corner frequency in stochastic synthesis of ground motion from finite-fault modeling are introduced, and conceptual disadvantages of the two are discussed in this paper. Furthermore, the non-uniform radiation of seismic wave on the fault plane, as well as the trend of the larger rupture area, the lower corner frequency, can be described by the source spectral model developed by the authors. A new dynamic corner frequency can be developed directly from the model. The dependence of ground motion on the size of subfault can be eliminated if this source spectral model is adopted in the synthesis. Finally, the approach presented is validated from the comparison between the synthesized and observed ground motions at six rock stations during the Northridge earthquake in 1994.
\end{abstract}

Key words: source spectral model; dynamic corner frequency; stochastic synthesis; finite-fault CLC number: P315.9 Document code: A

\section{Introduction}

In stochastic finite-fault modeling for estimating near-field strong ground motion, the fault is divided into many subfaults, and each subfault is treated as a point source. The acceleration Fourier spectrum at a site from a subfault is given by

$$
\begin{aligned}
A_{\mathrm{F}}\left(M_{0}, f, R\right)= & S\left(M_{0}, f\right) \cdot G(R) . \\
& D(R, L) \cdot A(f) \cdot P(f) \cdot I(f),
\end{aligned}
$$

where $A_{\mathrm{F}}\left(M_{0}, f, R\right)$ is the Fourier amplitude spectrum of ground motion at a site with distance $R, S\left(M_{0}, f\right)$ is the source spectrum, $G(R)$ accounts for the geometrical attenuation along the distance, $D(R, f)$ represents the energy dissipation attenuation, $A(f)$ is near surface amplification factor and could be estimated by a transfer function of regional crust velocity gradient, $P(f)$ is a high-cut filter, and $I(f)$ denotes the relation between the acceleration spectrum and displacement spectrum. Time series from a sub-source is derived from equation (1) by inverse Fourier transform, and the time history at the site can be obtained by superposition of seismograms

\footnotetext{
* Received 8 January 2009; accepted in revised form 14 April 2009; published 10 June 2009.

• Corresponding author. e-mail: vshermione@126.com
}

from all the sub-sources with time delays.

The synthesis should be subfault size independent, which means the synthesized ground motion do not change significantly with the subfault size variation, otherwise the synthesis technique is defective.

\section{Static corner frequency}

One famous stochastic finite-fault technique is the static corner frequency approach proposed by Beresnev and Atkinson (1998a), in which the acceleration source spectrum of a sub-source is defined as

$$
S_{a}(f)=\frac{C m_{0}(2 \pi f)^{2}}{1+\left(\frac{f}{f_{\mathrm{c}}}\right)^{2}},
$$

where $C$ is a constant (Boore, 2003); $m_{0}=\Delta \sigma \Delta l^{3}$ is the subfault moment; $\Delta \sigma$ is stress drop; $\Delta l$ is the subfault size; $f_{\mathrm{c}}=y z \beta / \pi \Delta l$ is the corner frequency; $\beta$ is the shear-wave velocity; $y$ is the ratio of the rupture velocity to $\beta$, generally taken as 0.8 or 0.85 ; and $z$ is the high-frequency radiation factor, which directly controls the maximum slip velocity on the fault plane (Beresnev and Atkinson, 1997). The static corner frequency approach requires subfault being multi-triggered to match 
the total seismic moment, which is physically difficult to explain. In addition, the summed acceleration amplitude spectrum at high-frequency range $\left(f>f_{\mathrm{c}}\right)$ could be deduced based on equation (2) as follows:

$$
a(f)=C \sqrt{\Delta \sigma M_{0}}\left(\frac{y z \beta}{\pi}\right)^{2} \frac{1}{\sqrt{\Delta l}} .
$$

Equation (3) shows an obvious dependence of amplitude spectrum on subfault size $\Delta l$. Beresnev and Atkinson (1998b) suggested a proper subfault size range of 5-15 $\mathrm{km}$, otherwise the synthesis is unreliable.

Motazedian and Atkinson (2002) once pointed out another conceptual disadvantage of the static corner frequency approach. They believed that the frequency content of seismic waves depends on the fault size. Larger earthquakes generally produce richer lower frequency than smaller earthquakes, like the double-bass producing lower frequencies than the violin due to the longer length of the strings. If considering the subfault and the entire fault as violin and double bass, it seems that static corner frequency approach is asking an orchestra full of small violins to produce double-bass music. No matter how to arrange and superpose the ground motions from subfaults, the rich low-frequency content of seismic wave is difficult to be simulated.

\section{Dynamic corner frequency}

In order to cover the shortage of the static corner frequency approach, Motazedian and Atkinson (2005) developed a stochastic approach based on dynamic corner frequency in which the acceleration source spectrum from the $i j$-th sub-source is as follows:

$$
S_{a i j}(f)=\frac{C M_{0 i j} H_{i j}(2 \pi f)^{2}}{1+\left(\frac{f}{f_{\mathrm{c} i j}}\right)^{2}},
$$

where $H_{i j}$ is the scaling factor to conserve the highfrequency spectral level of subfaults; $f_{\text {cij }}$ is the corner frequency depending on $N_{R}$, the cumulative number of subfaults ruptured by the time of the $i j$-th subfault being triggered:

$$
f_{\mathrm{c} i j}=4.9 \times 10^{6} \beta \sqrt[3]{\frac{\Delta \sigma}{M_{0 \mathrm{av}} N_{R}}}
$$

The initial intent of Motazedian and Atkinson (2005) is truly good. They wanted to describe the non-uniformly radiated frequency content of seismic wave on the fault plane by assigning different corner frequency to each subfault and take into account the trend of corner frequency decreasing as rupture develops. However, in the author's opinion, two latent drawbacks in the dynamic corner frequency approach are deserved to be discussed in detail.

First, according to equation (6), the corner frequency of the subfault, where the rupture starts, is the largest and corner frequencies of the rest subfaults reduces gradually in terms of the rupture order. Motazedian and Atkinson (2005) defined this trend of corner frequency to describe the large radiation of the high-frequency energy when the rupture starts and the total energy distributing towards low-frequencies as the rupture develops. However, it is well-known that asperity is the stiffer area on the fault plane. The rapid rise of dislocation and quick release of stress caused by the rupture of the asperity produce large high-frequency seismic wave, even more than the rupture starting area (Zheng and Yao, 1993; Somerville et al, 1999; Miyake et al, 2003). Therefore, the definition in equation (6) actually weakens the contribution of the asperity subfault to the high-frequency energy.

Second, according to equation (6), the corner frequency of the first subfault, where the rupture starts, is computed in terms of $M_{0 \mathrm{av}}$, because only one subfault is triggered; from the second subfault on, the corner frequency is calculated with $M_{0 \text { av }} N_{R}$; when the rupture terminates, all subfaults are triggered, then the corner frequency of the last ruptured subfault should be computed with $M_{0 \text { av }} N=M_{0}$. This must result in the underestimation of the subfault corner frequency. Considering the dependence of the high-frequency spectral level from a sub-source on the corner frequency $A_{i j}(f)_{f>>c i j} \propto f_{\mathrm{c} i j}^{2}$ (Motazedian and Atkinson, 2005), this underestimation of corner frequency will hence result in the underestimation of the sub-source spectral level and the summed ground motions. Motazedian and Atkinson (2005) also recognized this underestimation, so they employed a scaling factor $H_{i j}$ in equation (5) for compensation. However, $H_{i j}$ is deduced based on a hypothesis that "the high-frequency energy radiated from each subfault should be the same if all subfaults are identical", it can not represent the non-uniformly radiation of highfrequency seismic wave as discussed previously. Motazedian and Atkinson (2005) listed a few references (Boore, 1983; Boatwright and Choy, 1992; Hough and Dreger, 1995; Hirasawa and Stauder, 1965) to prove the 
inverse relation between the corner frequency and the ruptured area or duration, but the authors note that these references all discuss about the relation between the corner frequency of the far-field spectrum radiated from a small finite source and the ruptured area (or duration) of the same source. In stochastic finite-fault modeling, each subfault is treated as such small finite source, so the corner frequency of subfault should be controlled by the subfault characteristics instead of by the entire fault characteristics. Certainly, the characteristics of the entire fault should be considered but can not be the dominate factor, otherwise the subfault corner frequency and the spectral level tends to be underestimated.

\section{Source spectral model considering dynamic corner frequency}

Inspired by dynamic corner frequency, we consider that the corner frequency should be different for all subfaults and the effect of rupture process should be taken into account in the sub-source spectrum. Thus, the corner frequency for the $i j$-th subfault is defined as:

$$
f_{\mathrm{c} i j}=4.9 \times 10^{6} \beta_{3} \sqrt{\frac{\Delta \sigma}{M_{0 i j}}},
$$

where $M_{0 i j}$ is subfault moment given by

$$
M_{0 i j}=\frac{M_{0} D_{i j}}{\sum_{k=1}^{n_{l}} \sum_{l=1}^{n_{w}} D_{k l}},
$$

where $D_{i j}$ is the slip of the $i j$-th subfault; $n_{l}$ and $n_{w}$ are separately the numbers of subfaults along strike and dip directions.

A source spectral model developed by Wang (2001) is adopted to describe the variation of corner frequency with the rupture development. The spectral model is of the following form:

$$
S_{a}(f)=\frac{M_{0}(2 \pi f)^{2}}{\left[1+\left(\frac{f}{f_{\mathrm{c}}}\right)^{a}\right]^{b}},
$$

where coefficients $a$ and $b$ are given by

$$
\left\{\begin{array}{l}
a=3.05-0.33 M_{\mathrm{W}} \\
b=\frac{2}{a}
\end{array} .\right.
$$

$M_{\mathrm{W}}$ in equation (9) stands for the moment magnitude. This model is very close to Brune's model for small magnitude; and for large magnitude, in mid- and lowfrequency range, the spectral curve drops rapidly as the Atkinson's double corner frequency model does.

Equation (9) together with a relation between the rupture area and the magnitude could connect the corner frequency to the ruptured area. Many studies presented so far focus on such relations (Gutenberg and Richter, 1956; Kanamori and Anderson, 1975; Hanks and Kanamori, 1979; Sato, 1979; Wells and Coppersmith, 1994; Somerville et al, 1999), and the one $\lg S=$ $0.88 M_{\mathrm{W}}-3.29$ proposed by Wang (2004) was adopted herein. Substituting the relation into equation (9) yields

$$
\left\{\begin{array}{l}
a=-0.375 \lg S+1.81625 \\
b=\frac{2}{a}
\end{array},\right.
$$

where $S$ refers to the total area of the ruptured subfaults by the moment of the $i j$-th subfault triggered:

$$
S_{i j}=N_{R} \cdot \Delta L \cdot \Delta W,
$$

where $\Delta L$ and $\Delta W$ stand for the subfault size along strike and dip directions respectively. Equation (6) together with equations (8), (10) and (11) forms the source spectral model considering dynamic corner frequency. As long as the slip distribution on the fault plane is non-uniform, the corner frequency for all subfaults is different; the larger slip, the smaller corner frequency, which covers the shortage discussed in the previous section. In addition, " $a$ " is logarithm-dependent on the ruptured area, and the product of " $a$ " and " $b$ " was fixed as two. These performances decide that the variation of the ruptured area will not affect the spectral level significantly.

\section{A case of strong ground motion syn- thesis}

In order to validate the availability of the new spectral model for strong ground motion synthesis, the Northridge earthquake with $M_{\mathrm{W}} 6.7$ occurred in 1994 was used. The source parameters are listed in Table 1 and the slip distribution on the fault plane adopted from Wang (2004) is illustrated in Figure 1. The location of the rupture start point is marked with cross in Figure 1. The fault model was divided into subfaults of $1 \mathrm{~km}$ by 1 $\mathrm{km}$, ground motion from each subfault was computed by equation (1) in which $S\left(M_{0}, f\right)$ and corner frequency $f_{\mathrm{c}}$ were calculated by equations (8) and (6) respectively. Attenuation parameters used in synthesis were listed in 
Table 2 (Beresnev and Atkinson, 1998a).

Ground motions from the finite-fault model for the six rock sites, that is, ANB, BCY, L4B, L4N, LWE and PCD, which well recorded the Northridge earthquake, were synthesized. The hypocentral distance is 66.31, $29.05,52.92,52.91,25.82$ and $26.85 \mathrm{~km}$, respectively. The synthesized acceleration response spectra (ARSs) with $5 \%$ damping ratio are shown together with those from the observed records in Figure 2, from which one can observe that the synthesized ARS well agrees with the observed for the period range of lower than $1 \mathrm{~s}$.

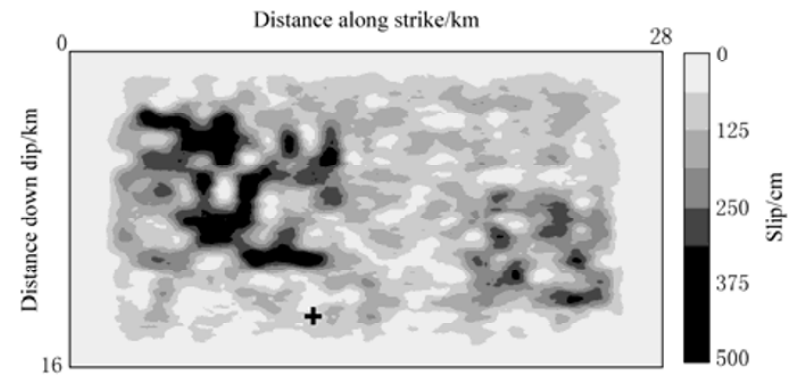

Figure 1 Finite fault source model of the Northridge $M_{\mathrm{W}} 6.7$ earthquake in 1994. The cross denotes the location of the rupture start point.

Table 1 Source parameters of the Northridge $M_{\mathrm{W}} 6.7$ earthquake in 1994

\begin{tabular}{|c|c|c|c|c|c|c|c|c|}
\hline \multicolumn{2}{|c|}{ Orientation } & \multirow{2}{*}{ Dimension } & \multirow{2}{*}{$\begin{array}{l}\text { Depth } \\
\text { /km }\end{array}$} & \multirow{2}{*}{$\begin{array}{l}\text { Moment } \\
/ 10^{19} \mathrm{~N} \cdot \mathrm{m}\end{array}$} & \multirow{2}{*}{$\begin{array}{l}\text { Stress drop } \\
\quad / \mathrm{MPa}\end{array}$} & \multirow{2}{*}{$\begin{array}{c}\text { Crustal density } \\
/ \mathrm{g} \cdot \mathrm{cm}^{-3}\end{array}$} & \multirow{2}{*}{$\begin{array}{l}\text { Crustal shear wave } \\
\text { velocity } / \mathrm{km} \cdot \mathrm{s}^{-1}\end{array}$} & \multirow{2}{*}{$\begin{array}{l}\text { Rupture velocity } \\
\qquad / \mathrm{km} \cdot \mathrm{s}^{-1}\end{array}$} \\
\hline Strike/ ${ }^{\circ}$ & Dip/ ${ }^{\circ}$ & & & & & & & \\
\hline 122 & 40 & $28 \mathrm{~km} \times 16 \mathrm{~km}$ & $5-21$ & 1.2162 & 5 & 2.8 & 3.7 & $0.8 \beta$ \\
\hline
\end{tabular}

Table 2 Attenuation parameters in stochastic synthesis

\begin{tabular}{ccccc}
\hline$Q(f)$ & Distance-dependence duration & Geometric spreading & Local amplification & Kappa factor \\
\hline \multirow{2}{*}{$150 f^{0.5}$} & $T_{0}+0.1 R$ & $\begin{array}{l}1 / R(R \text { in unit of } \mathrm{km}) \text { for } R \leq 70,1 / R^{0} \text { for } \\
70<R<130 \text { and } 1 / R^{0.5} \text { for } R \geq 130\end{array}$ & From Boore and Joyner (1997) & 0.05 \\
\hline
\end{tabular}
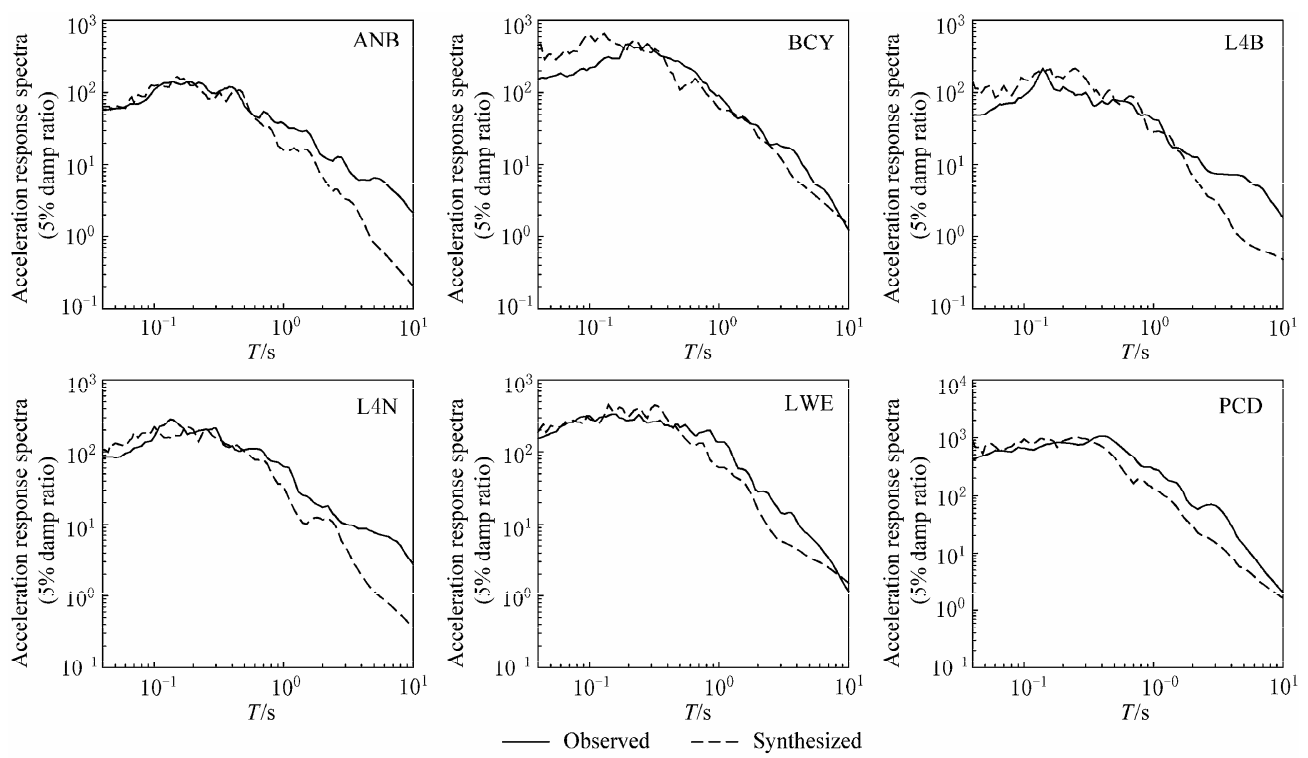

Figure 2 Comparison of the synthesized and observed acceleration response spectra.

We also validated the subfault size dependence of the new model based on station LWE. The source parameters and attenuation parameters were all kept the values listed in Tables 1 and 2. The finite-fault model is divided in sequence into subfaults of $1 \mathrm{~km}$ by $1 \mathrm{~km}, 2 \mathrm{~km}$ by $2 \mathrm{~km}$ and $4 \mathrm{~km}$ by $4 \mathrm{~km}$. ARSs from the static corner frequency approach, the dynamic corner frequency approach and the new approach were worked out and com- pared with that from the records as shown in Figure 3.

It is easy to see from Figure 3 that the synthesized ARSs from the static corner frequency approach decreases as the subfault size increases at the periods shorter than $1 \mathrm{~s}$, which agrees with the inverse relation in equation (3); but for the periods longer than $1 \mathrm{~s}$, the synthesized ARSs shows the opposite trend. Considering the accuracy of stochastic technique (Sun and Tao, 2008), 

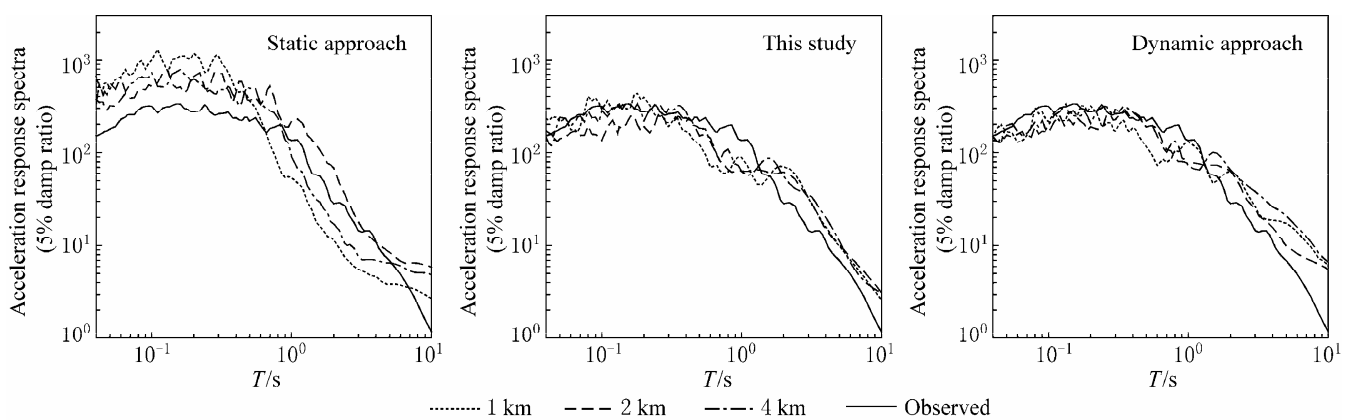

Figure 3 Comparison of the synthesized acceleration response spectra with different subfault sizes and the observed.

the further discussion only focuses on the shorter period range. Figure 3 also shows that, even the subfault size is $4 \mathrm{~km}$, the synthesized ARS from the static corner frequency approach is still not satisfactory. By contrast, the synthesized ARS from the dynamic corner frequency approach for all the cases is similar, and so does the synthesized ARS from the new approach. This indicates that the improvement made in this paper eliminates the subfault size dependence as well as the dynamic corner frequency does, and what is more, it covers the shortage of the original dynamic corner frequency approach. The new approach thus is effective for the near-field strong ground motion estimation.

\section{Conclusions}

A source spectral model considering dynamic corner frequency is developed in this paper in order to better synthesize ground motions, especially in near field. This model covers the shortage of the original dynamic corner frequency approach in the description of the non-uniform radiation of seismic wave contents. It also considers the downtrend of corner frequency with the rupture development and avoids the significant underestimation of the spectral level caused by the variation of the cumulative ruptured area. Validation based on the synthesis for the six rock stations of the Northridge $M_{\mathrm{W}} 6.7$ earthquake demonstrates that the proposed approach is effective and reliable, and could eliminate the subfault size dependence of the synthesis.

In fact, the idea in this study that considering the effect of rupture process on corner frequency is inspired by the original dynamic corner frequency definition, but strictly speaking, the improvement made in this paper forms a new dynamic corner frequency.

Acknowledgements This study is supported by National Natural Science Foundation of China under grant No. 50778058 and 90715038, National Key Technology Research and Development Program under grant No. 2006BAC13B02. Authors especially appreciate Dr. Durish Motazedian and Dr. Igor Beresnev for their great helps. We thank also Dr. Hoboo Ha for his help on English writing. Referees, the editor-in-chief and the editor are also appreciated for their hard work.

\section{References}

Beresnev I A and Atkinson G (1997). Modeling finite-fault radiation from the $\omega^{n}$ spectrum. Bull Seism Soc Amer 87(1): 67-84.

Beresnev I A and Atkinson G (1998a). Stochastic finite-fault modeling of ground motions from the 1994 Northridge, California, earthquake (I): Validation on rock sites. Bull Seism Soc Amer 88(6): 1 392-1 401.

Beresnev I A and Atkinson G (1998b). FINSIM — a FORTRAN program for simulating stochastic acceleration time histories from finite faults. Seism Res Lett 69(1): 27-32, http://http-server.carleton.ca/ dariush/research/ SSA2002.pdf.

Boatwright J and Choy G (1992). Acceleration source spectra anticipated for large earthquakes in northeastern North America. Bull Seism Soc Amer 82: $660-682$.

Boore D (1983). Stochastic simulation of high-frequency ground motions based on seismological models of the radiated spectra. Bull Seism Soc Amer 73: $1865-1894$.

Boore D M (2003). Simulation of ground motion using the stochastic method. Pure Appl Geophys 160: 635-676.

Boore D M and Joyner W B (1997). Site amplifications for generic rock sites. Bull Seism Soc Amer 87: 327-341.

Gutenberg B and Richter C F (1956). Magnitude and energy of earthquakes. Ann Geofis 9: 1-15.

Hanks T C and Kanamori H (1979). A moment-magnitude scale. J Geophys Res 84: 2 348-2 350 .

Hirasawa T and Stauder W (1965). On the seismic body waves from a finite moving source. Bull Seism Soc Amer 55: 237-262.

Hough S and Dreger D (1995). Source parameters of the 23 April 1992 M6.1 Joshua Tree, California, earthquake and its aftershocks: Empirical Green's function analysis of GEOS and TERRAscope data. Bull Seism Soc Amer 85: 1 576-1 590.

Kanamori H and Anderson D L (1975). Theoretical basis of some empirical relations in seismology. Bull Seism Soc Amer 65: 1 073-1 096.

Miyake H, Iwata T and Irikura K (2003). Source characterization for broadband ground-motion simulation: Kinematic heterogeneous source model and strong motion generation area. Bull Seism Soc Amer 93(6): 2 531-2 545.

Motazedian D and Atkinson G M (2002). Dynamic corner frequency: a new concept in stochastic finite fault modeling. Seismological Society of America Meeting. April 17-19, Victoria, British Columbia. 
Motazedian D and Atkinson G M (2005). Stochastic finite-fault modeling based on a dynamic corner frequency. Bull Seism Soc Amer 95(3): 9951010

Sato R (1979). Theoretical basis on relationships between focal parameters and earthquake magnitude. J Phys Earth 27: 353-372.

Somerville P G, Irikura K, Graves R W, Wald D, Abrahamson N, Iwasaki Y, Kagawa T, Smith N and Kowada A (1999). Characterizing crustal earthquake slip models for the prediction of strong ground motion. Seism Res Lett 70(1): 59-80.

Sun X D and Tao X X (2008). Superposition of ground motions at low and high frequencies in synthesis. The 14th World Conference on Earthquake Engineering. October 12-17, Beijing, China.
Wang G X (2001). Strong Ground Motion Attenuation. Ph D Thesis, Institute of Engineering Mechanics, China Earthquake Administration, Harbin, China, 70-71 (in Chinese).

Wang H Y (2004). Finite Fault Source Model for Predicting Near-Field Strong Ground Motion. Ph D Thesis, Institute of Engineering Mechanics, China Earthquake Administration, Harbin, China, 27, 83 (in Chinese).

Wells D L and Coppersmith K J (1994). New empirical relationships among magnitude, rupture length, rupture width, rupture area, and surface displacement. Bull Seism Soc Amer 84(4): 974-1 002.

Zheng T Y and Yao Z X (1993). Source process study of the Tangshan earthquake using the near-field records. Acta Geophysica Sinica 36(2): 174-184 (in Chinese with English abstract). 